\title{
Velocity and concentration distributions in turbulent odor plumes in the presence of vegetation mimics: a flume study
}

\author{
Christopher M. Finelli* \\ Louisiana Universities Marine Consortium, 8124 Highway 56, Chauvin, Louisiana 70344, USA
}

\begin{abstract}
Many marine animals use olfaction to search for vital resources (e.g. food, mates), and their success depends on the complex structure of turbulent odor plumes. To better understand chemically mediated interactions it is necessary to empirically measure the relationship between turbulent water flow and odor distribution in a variety of settings. Marsh edge habitats are important nursery and foraging areas for resident and transient estuarine species. The presence of emergent vegetation in these habitats can have a strong influence on the ambient turbulence regime, as well as the dispersal of water-borne odors. To quantify the effects of vegetation-like structure on odor dispersal, I measured velocity and concentration fluctuations in artificial 'odor' plumes created in a laboratory flume. Time-series measurements of velocity and concentration were made simultaneously at the same spatial location using a thermistor flowmeter combined with a conductivity microprobe. Flow speed (advection) controlled odor dilution and odor filament dispersal throughout the plume; plumes generated in $5 \mathrm{~cm} \mathrm{~s}^{-1}$ flows had higher mean concentrations, and were characterized by fewer odor filaments that were more concentrated and of longer duration than plumes generated in $12 \mathrm{~cm} \mathrm{~s}^{-1}$ flows. In contrast, adding Spartina alterniflora mimics upstream of the plume source primarily altered odor filament properties; the presence of upstream structure created more abundant odor filaments that were more dilute and of shorter duration relative to smooth-bottomed treatments. Importantly, such changes to the odor plume structure can alter the success of odor mediated search, although further studies are needed to show if this effect will be positive or negative.
\end{abstract}

KEY WORDS: Odor plume $\cdot$ Hydrodynamics $\cdot$ Turbulence $\cdot$ Microscale Resale or republication not permitted without written consent of the publisher

\section{INTRODUCTION}

Chemical information permeates marine environments and the importance of this information for the ecology of marine organisms is undisputed. Dissolved and adsorbed compounds mediate processes ranging from larval settlement (positive and negative cues, metamorphosis induction) to foraging (attraction and deterrence) and mating (mate attraction, mass spawning). Classically, the study of chemical ecology has focused on the identification and purification of the myriad compounds used in these interactions (e.g.

*E-mail: cfinelli@lumcon.edu
Valentinčič 1991, Pawlik 1992, Nevitt et al. 1995, Decho et al. 1998). While this research is critical to our understanding of compound synthesis and detection, the factors which contribute to the dispersal and transport of chemical signals are equally important to understanding the ecological and behavioral components of chemoreception. This is especially true for dissolved compounds (e.g. odors), whose distributions in space and time are intimately tied to the ambient flow regime.

Research focusing on the link between hydrodynamics, odor signal structure, and animal performance has led to a fundamental shift in our understanding of chemical plumes and how they are perceived by navigating organisms. It is now commonly accepted that the 
distribution of odorant within plumes is patchy, rather than the stable gradient predicted by time-averaged (Gaussian) models (e.g. Murlis \& Jones 1981, Atema 1985, Moore \& Atema 1988, 1991, Zimmer-Faust et al. 1988, 1995, Moore et al. 1991, Finelli et al. 1999). Furthermore, properties associated with individual odor patches (Moore \& Atema 1988, Zimmer-Faust et al. 1988, Moore et al. 1994) and mechanical information provided by flowing water (Matthewson \& Hodgson 1972, Weissburg \& Zimmer-Faust 1993, Zimmer-Faust et al. 1995, Atema 1996, Finelli et al. 2000) may be used during orientation to plumes. These findings, among others, necessitate a more general understanding of hydrodynamics and odor dispersal processes in a variety of habitats. Unfortunately, our knowledge of odor plume structure, especially with reference to prevailing hydrodynamic conditions, is restricted to a handful of studies conducted in the laboratory (Moore \& Atema 1988, 1991, Weissburg \& Zimmer-Faust 1993, Moore et al. 1994) or simplified field settings (Zimmer-Faust et al. 1995, Finelli et al. 1999). As such, manipulative studies are critically needed to determine how odor dispersal patterns respond to the fluid dynamics that characterize different habitat types.

Salt marshes serve as critical habitat for adult and juvenile crustaceans and fishes (e.g. Kneib 1997 , Minello \& Webb 1997). The marsh edge, in particular, is an area of focused activity for estuarine predators and prey (Baltz et al. 1993, Minello et al. 1994, Peterson \& Turner 1994). For example, Micheli (1996, 1997) showed that blue crabs Callinectes sapidus use marsh edge habitats more frequently and have higher predation rates in these habitats than in adjacent sandy bottom areas. She hypothesized that blue crabs were benefitting from increased prey density and protection from predatory birds among the shoots of emergent vegetation. Micheli's findings are particularly intriguing because blue crabs seem to be exploiting a habitat traditionally regarded as an area of prey refuge (Baltz et al. 1993, Micheli 1996, Kneib 1997). In this study I begin to address whether the physical-chemical environment of the marsh edge facilitates the odormediated foraging of blue crabs and other organisms.

Partially submerged beds of vegetation (e.g. Spartina alterniflora) are characteristic of tidal marshes and play an important role in the hydrography of these habitats (e.g. Eckman 1983, Nowell \& Jumars 1984, Leonard \& Luther 1995, Sand-Jensen \& Mebus 1996). For example, Leonard \& Luther (1995) showed that both mean velocity and turbulence intensity decrease among stands of $S$. alterniflora and other marsh vegetation. They argued that stands of emergent vegetation act as a baffle that retards flow through the marsh canopy and redistributes turbulent energy from larger to smaller eddies.
Such habitat-specific changes in mean flow and turbulence properties can have pronounced effects on both odor dispersal and orientation behavior. For example, Finelli et al. (1999) demonstrated how gross plume morphology was related to the variable eddy sizes within tidal flows. Moreover, Weissburg \& Zimmer-Faust (1993) showed that foraging by blue crabs is sensitive to both mean flow and turbulence. Specifically, blue crabs were less efficient and less successful in orienting to odor plumes in flows with increased turbulence. They concluded that increased turbulent mixing caused more rapid dilution of the plume, thereby decreasing the ability of blue crabs to detect the odor signal. Thus, depending on the nature and magnitude of changes in turbulence induced by stands of emergent vegetation, the success of odor-mediated search may be enhanced or diminished.

To determine how emergent vegetation affects odor dispersal, I performed a flume study during which odor concentration and velocity were measured simultaneously throughout tracer plumes. I conducted these studies at 2 flow speeds and in the presence or absence of structures mimicking emergent vegetation. To simplify this initial flume study, I consider the effects of structure on odor dispersal in downstream clearings rather than inside the canopy where searching may be further constrained. As did Leonard \& Luther (1995), I found that vegetation-like structure decreased turbulence intensity and redistributed turbulent kinetic energy from larger to smaller eddies. Turbulence properties in the presence of upstream structure resulted in more diffuse plumes and more numerous individual odor filaments. Such changes in plume structure are likely to alter the ability of organisms to successfully search in vegetated habitats compared to adjacent smooth-bottomed habitats, although further studies are needed to tease apart these effects.

\section{MATERIALS AND METHODS}

The experiment. I tested the effects of flow speed and emergent vegetation on odor dispersal in a laboratory flume using 2 flow speeds ( 5 and $\left.\sim 12 \mathrm{~cm} \mathrm{~s}^{-1}\right)$ and 2 vegetation mimic treatments (present and absent). Tracer plumes of an ethanol-salt solution were introduced into flowing freshwater while concentration and velocity were measured at 40 locations in each plume. The ethanol-salt mixture was used as an easily measurable odor analog with dispersal properties similar to other water soluble compounds (for similar examples of this technique see Moore \& Atema 1988, Bara et al. 1992).

I performed these studies in a racetrack flume housed at the Louisiana Universities Marine Consortium (LUMCON) Defelice Marine Center in Cocodrie, 
Side View of Drive Mechanism
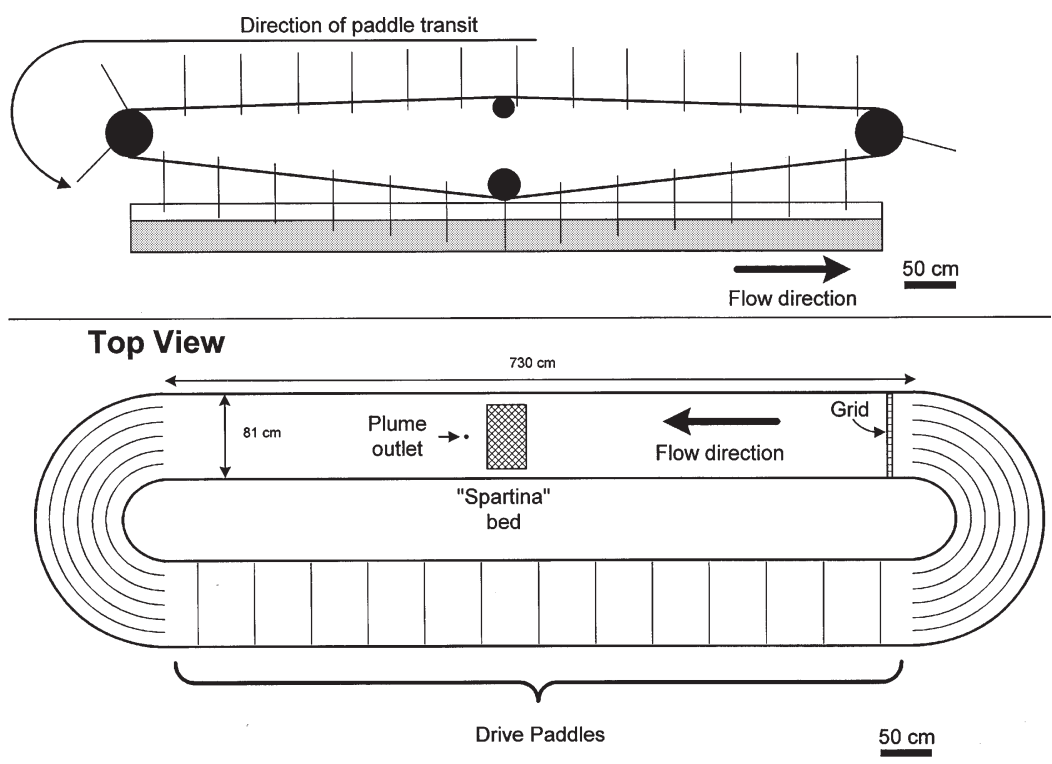

Fig. 1. Design and layout of the LUMCON flume. Side view of drive mechanism shows the vertical entry and exit of paddles. Top view of the flume shows relative positions of experimental apparatus

LA, USA (Fig. 1). The LUMCON flume is oval, with the straight portions of the flume measuring $730 \mathrm{~cm}$ in length (Fig. 1). The channel width is $81 \mathrm{~cm}$ at all points and depth was held at $30 \mathrm{~cm}$. At this depth, the water volume in the flume is $\sim 4900 \mathrm{l}$. Water flow is driven by a series of paddles attached to a caterpillar-type drive mechanism. The paddles enter and exit the water vertically to minimize the creation of secondary flows (Fig. 1). A $5.5 \mathrm{~cm}$ thick plastic baffle $(1 \times$ $1 \mathrm{~cm}$ grid) is located at the extreme upstream position on the 'working' side of the flume to reduce large-scale flow disturbances introduced by paddle motion or flume turns. The flume was filled with fresh tap water at least $48 \mathrm{~h}$ prior to each trial. Three replicate trials were completed on separate days with all 4 treatments being performed in a single day.

Flow speed treatments were chosen to represent high $\left(12 \mathrm{~cm} \mathrm{~s}^{-1}\right)$ and low $\left(5 \mathrm{~cm} \mathrm{~s}^{-1}\right)$ flows present in Spartina alterniflora dominated high marsh areas (Leonard \& Luther 1995), and to present conditions under which blue crabs can successfully forage in the field (Zimmer-Faust et al. 1995, Finelli et al. 2000). Flow speed was set each morning by measuring the transit time of dye released in a $50 \mathrm{~cm}$ section of the flume, and subsequently confirmed using a thermistor flow meter. Two vegetation mimic treatments, present and absent, were also conducted. For these preliminary studies, I chose to control 'vegetation' geometry and distribution by using $0.8 \mathrm{~cm}$ diameter wood dowels to simulate $S$. alterniflora stems. I arranged 57 dowels in a $61.2 \times 34.5 \mathrm{~cm}$ staggered grid with $7 \mathrm{~cm}$ between dowels (Fig. 2), resulting in a final stem density of $270 \mathrm{~m}^{-2}$. This density falls well within natural densities studied elsewhere (Eckman 1983, Leonard \& Luther 1995).

I created 'odor' plumes by continuously releasing a dyed salt-ethanol solution into the flowing freshwater. The tracer solution consisted of a 77:23 mixture, by volume, of $50 \%$ brine (Crystal Sea Marine Mix, Marine Enterprises International, Baltimore, MD, USA, dissolved in distilled water) and $100 \%$ ethanol (Louisiana State University Medical School Supply). Fluorescein dye was added at $0.1 \mathrm{~g} \mathrm{l}^{-1}$ and the final solution was filtered to remove undissolved salt. This mixture was developed by trial and error to produce a solution equal in density to flume water but with an increased conductivity (Table 1). The nominal conductivity of the tracer solution was measured with an Orion Model 125 conductivity meter, and its density matched that of the flume water to within $0.15 \%$ on each trial day (Table 1 ).
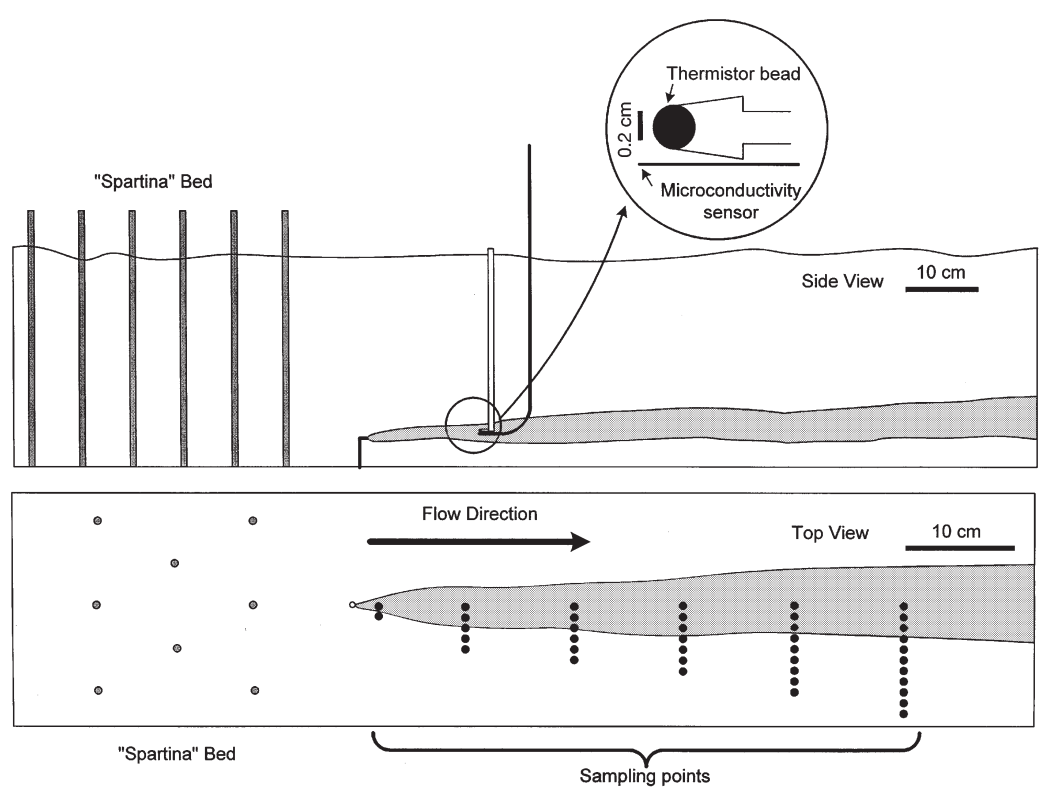

Fig. 2. Top and side views of the experimental array showing the relative size and position of the plume outlet, vegetation mimics ('Spartina bed'), sensors, and sampling points 
Table 1. Temperature, density, and conductivity of flume water and conductivity solution for each trial day. Temperature, density, and conductivity of the tracer solution were measured at the start of each day. Mean densities $( \pm 1$ SD) are taken from 10 replicate measurements, while mean conductivities for flume water are taken from measurements made at the beginning and end of each treatment run $(n=8)$

\begin{tabular}{|lccccccc|}
\hline \multirow{2}{*}{ Trial } & \multicolumn{3}{c}{ Flume water } & & & \multicolumn{2}{c|}{ Conductivity solution } \\
\cline { 2 - 4 } & Temp. $\left({ }^{\circ} \mathrm{C}\right)$ & Density $\left(\mathrm{g} \mathrm{l}^{-1}\right)$ & Conductivity $(\mathrm{mS})$ & & Temp. $\left({ }^{\circ} \mathrm{C}\right)$ & Density $\left.(\mathrm{g} \mathrm{l})^{-1}\right)$ & Conductivity $(\mathrm{mS})$ \\
\hline 1 & 19.5 & $0.9950( \pm 0.0012)$ & $0.559( \pm 0.008)$ & & 19.9 & $0.9963( \pm 0.0010)$ & 32.7 \\
2 & 17.1 & $0.9974( \pm 0.0011)$ & $0.563( \pm 0.007)$ & & 17.6 & $0.9988( \pm 0.0023)$ & 32.1 \\
3 & 18.0 & $1.0003( \pm 0.0010)$ & $0.502( \pm 0.008)$ & & 20.8 & $1.0018( \pm 0.0025)$ & 33.9 \\
\hline
\end{tabular}

The tracer solution was gravity fed from a medical enteral feeding bag (Ross Industries Toptainer, Colum-

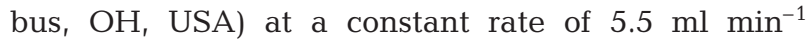
through an orifice located $4.0 \mathrm{~cm}$ from the flume bottom and $410 \mathrm{~cm}$ from the upstream plastic baffle (Figs. 1 \& 2). Given a plume outlet diameter of $0.2 \mathrm{~cm}$, the inlet velocity was $\sim 2.9 \mathrm{~cm} \mathrm{~s}^{-1}$ and the jet Reynolds number $\left(\mathrm{Re}_{\mathrm{jet}}\right)$ was $\sim 58$. Once the tracer plume was established, conductivity (linearly proportional to salt concentration) was measured at 40 locations within the plume (Fig. 2) using a microscale conductivity instrument (MSCI, Precision Measurement Engineering, Encinitas, CA, USA). The MSCI sensor is a 4 conductor-type conductivity electrode measuring $500 \mu \mathrm{m}$ in width. The MSCI was calibrated each day using 3 NIST (National Institute of Standards and Technology) traceable conductivity standards $(0.1,1.413$, and $10 \mathrm{mS}$ ) and the working 'odor' solution. The resulting linear calibrations had an average $r^{2}=0.9993$ $( \pm 0.0006 \mathrm{SD}, \mathrm{n}=3)$.

At each measurement location, I used a thermistor bead velocimeter (LaBarbara \& Vogel 1976) to measure flow velocity and turbulence intensity. For these studies turbulence intensity is defined as the rootmean square (RMS) turbulence intensity, which is the standard deviation of the velocity time series. The sensor was temperature compensated and calibrated each day. Velocity calibrations were performed by repeatedly moving the probe through a still water tank, while recording the output of the thermistor along with the output of a linear velocity transducer (LVT). Subsequently, the output of the thermistor was regressed against that of the LVT using King's Law (Hart et al. 1996). The resulting linear calibrations had a mean $\mathrm{r}^{2}=0.97( \pm 0.02 \mathrm{SD}, \mathrm{n}=3)$.

Conductivity and velocity measurements were collected at a rate of $8 \mathrm{~Hz}$ for $32 \mathrm{~s}$ with a Campbell CR10X datalogger. By choosing sensors with miniature components, velocity and conductivity were measured at essentially the same spatial location (Fig. 2). Paired measurements of velocity and conductivity were made at a single location during each sample period (32 s), after which the probes were moved to the next sample location. Sampling was begun at the plume center, $2 \mathrm{~cm}$ downstream from the plume source, and progressed cross-stream before moving to the next downstream location. To avoid confounding conductivity measurements with heat from the thermistor probe, the MSCI sensor was placed slightly upstream and below the thermistor bead (Fig. 2).

Data analysis. Mean velocities and RMS turbulence intensities from each measurement location were used to evaluate spatial variation in flow conditions within the plume. In addition, treatment mean velocities and turbulence intensities for each trial were calculated and are presented in Table 2. I used a 2-factor analysis of variance (ANOVA) to evaluate the influence of flow treatment and vegetation mimic treatment on the mean velocities and turbulence intensities.

Spectral analysis of each velocity time series was performed to determine the frequency characteristics of velocity for each treatment combination (e.g. Box et al. 1994). Each velocity time series was normalized with respect to its mean by subtracting the mean velocity from each individual data point. This allows spectral densities to be compared between treatments without regard for differences in mean velocity (SAS Institute 1993, Finelli et al. 1999). Each normalized time series was then windowed using a 256-point triangular (Bartlett) window (Press et al. 1992) before spectral analyses were completed using Fast-Fourier Transform methods (SAS Institute 1993). Composite spectral density plots were constructed for each day and treatment combination from the 40 individual plots generated from the raw data.

Concentration mean and standard deviation for each spatial location in each plume were calculated from individual time series. In addition, relative dilution rates between treatments were examined by normalizing each mean to the source conductivity, thus placing all concentration data on a relative scale from 0 to 1 . Using this scheme, cross-stream and downstream profiles can be compared regardless of the source conductivity. A 2-factor analysis of covariance (ANCOVA), 
Table 2. Flow speed and conductivity conditions for each replicate treatment on each trial. Composite mean $( \pm 1$ SD) flow speeds and root-mean square turbulence intensities (RMS TI) are taken from the 40 individual flow records collected during each trial. Conductivity data are background levels measured from the flume channel

\begin{tabular}{|c|c|c|c|c|c|c|}
\hline Trial & Flow & $\begin{array}{l}\text { Vegetation } \\
\text { mimic }\end{array}$ & $\begin{array}{l}\text { Flow speed } \\
\left(\mathrm{cm} \mathrm{s}^{-1}\right)\end{array}$ & $\begin{array}{l}\text { RMS TI } \\
\left(\mathrm{cm} \mathrm{s}^{-1}\right)\end{array}$ & $\begin{array}{l}\text { Beginning } \\
\text { cond. (mS) }\end{array}$ & $\begin{array}{c}\text { End } \\
\text { cond. (mS) }\end{array}$ \\
\hline 1 & $\begin{array}{l}\text { Slow } \\
\text { Slow } \\
\text { Fast } \\
\text { Fast }\end{array}$ & $\begin{array}{l}\text { Smooth } \\
\text { 'Vegetated' } \\
\text { Smooth } \\
\text { 'Vegetated' }\end{array}$ & $\begin{array}{r}4.43( \pm 0.22) \\
3.59( \pm 0.25) \\
11.28( \pm 0.34) \\
10.88( \pm 0.47)\end{array}$ & $\begin{array}{l}0.55( \pm 0.16) \\
0.37( \pm 0.17) \\
0.60( \pm 0.14) \\
0.47( \pm 0.21)\end{array}$ & $\begin{array}{l}0.547 \\
0.554 \\
0.564 \\
0.560\end{array}$ & $\begin{array}{l}0.553 \\
0.558 \\
0.571 \\
0.565\end{array}$ \\
\hline 2 & $\begin{array}{l}\text { Slow } \\
\text { Slow } \\
\text { Fast } \\
\text { Fast }\end{array}$ & $\begin{array}{l}\text { Smooth } \\
\text { 'Vegetated' } \\
\text { Smooth } \\
\text { 'Vegetated' }\end{array}$ & $\begin{array}{r}6.24( \pm 0.39) \\
6.37( \pm 1.00) \\
12.26( \pm 0.43) \\
12.26( \pm 0.26)\end{array}$ & $\begin{array}{l}0.84( \pm 0.17) \\
0.58( \pm 0.14) \\
0.62( \pm 0.20) \\
0.47( \pm 0.15)\end{array}$ & $\begin{array}{l}0.551 \\
0.558 \\
0.568 \\
0.563\end{array}$ & $\begin{array}{l}0.556 \\
0.563 \\
0.572 \\
0.569\end{array}$ \\
\hline 3 & $\begin{array}{l}\text { Slow } \\
\text { Slow } \\
\text { Fast } \\
\text { Fast }\end{array}$ & $\begin{array}{l}\text { Smooth } \\
\text { 'Vegetated' } \\
\text { Smooth } \\
\text { 'Vegetated' }\end{array}$ & $\begin{array}{r}5.56( \pm 0.34) \\
5.51( \pm 0.77) \\
13.60( \pm 0.80) \\
12.09( \pm 0.45)\end{array}$ & $\begin{array}{l}0.89( \pm 0.15) \\
0.73( \pm 0.21) \\
0.85( \pm 0.28) \\
0.78( \pm 0.24)\end{array}$ & $\begin{array}{l}0.490 \\
0.496 \\
0.508 \\
0.502\end{array}$ & $\begin{array}{l}0.496 \\
0.500 \\
0.514 \\
0.508\end{array}$ \\
\hline
\end{tabular}

with the $x$ - or $y$-position included as a covariate, was used to test for flow and vegetation mimic effects on normalized concentrations in the profiles. The data were arcsine transformed for statistical testing (Zar 1996).

Properties of individual odor filaments may be important to navigating organisms; therefore, I investigated the effects of flow speed and vegetation mimics on some of these properties. Individual odor filaments (peaks) were identified in each conductivity time series. The number of peaks, mean peak height, mean peak width, and intermittency were calculated for each conductivity time series. Intermittency is defined as the proportion of time conductivity remains above baseline values (Finelli et al. 1999). Centerline and cross-stream profiles are presented for all treatments. A series of 2-factor ANCOVAs, using the $x$ - or $y$ position as a covariate, was used to test the effects of flow and vegetation mimics on odor filament properties in these profiles. For statistical testing, intermittency was arcsine transformed, while peak height and peak width were log transformed (Zar 1996).

Because of the low sample size $(n=3)$, I conducted a post-hoc power test (Zar 1996) to determine the probability of wrongly accepting the null hypotheses. Power for the tests described above was generally very low $(<0.30)$; consequently the chance of falsely accepting a null hypothesis was $>70 \%$. Given this low statistical power, I considered tests with a p $<0.05$ as statistically significant, and $\mathrm{p}<0.15$ as marginally significant results. In addition, for each 2-factor ANOVA or ANCOVA a vegetation mimic $\times$ flow speed interaction term was tested and shown to be non-significant; therefore this interaction was not included in any further analyses.

Spectral analyses of each conductivity time series were also completed as described above for velocity time series. Spectral analyses were conducted on raw conductivity data, not the normalized values used to compare dilution rates. Because of spatial gradients in the spectral properties of time series of conductivity, composite plots of spectral density from the 3 trials were produced for each treatment and spatial location in the plume.

\section{RESULTS}

\section{Flow properties}

Mean velocity and turbulence intensity showed nearly constant distributions throughout the simulated odor plumes (Figs. $3 \& 4$ ). Flow velocity was slightly decreased and RMS turbulence intensity slightly increased at the center of the plume just downstream $(x=2 \mathrm{~cm})$ from the plume source, reflecting the influence of the plume outlet on flow conditions (Figs. 3 \& 4). This effect was consistent for all treatments and days, and flow properties return to background levels within the first $10 \mathrm{~cm}$ of the plume, indicating that for distances $>10 \mathrm{~cm}$ plume transport was dominated by general flume flow conditions.

The 2 flow treatments had significantly different mean flow speeds (ANOVA; $F_{1,9}=128.13, \mathrm{p}<0.001$ ), while vegetation mimics had no effect on mean flow speeds (ANOVA; $F_{1,9}=0.56, \mathrm{p}=0.474$ ). RMS turbulence intensities did not differ between flow treatments (ANOVA; $F_{1,9}=0.11, \mathrm{p}=0.752$ ); however, the presence of vegetation mimics marginally reduced turbulence intensity (ANOVA; $F_{1,9}=2.86, \mathrm{p}=0.125$ ).

Spectral analyses of velocity time series further illustrate the effects of vegetation mimics on turbulence in the flume. Patterns in the spectral density were consistent throughout each plume; therefore, I combined 


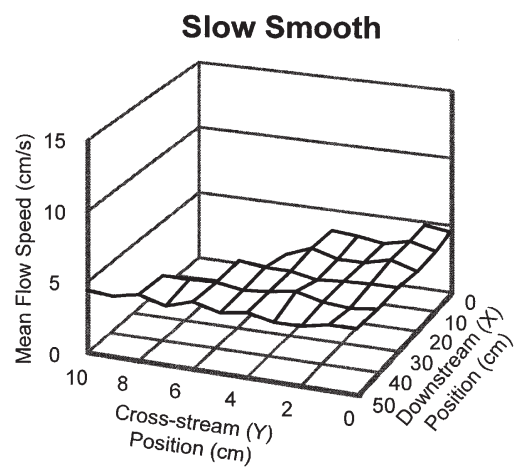

Fast Smooth
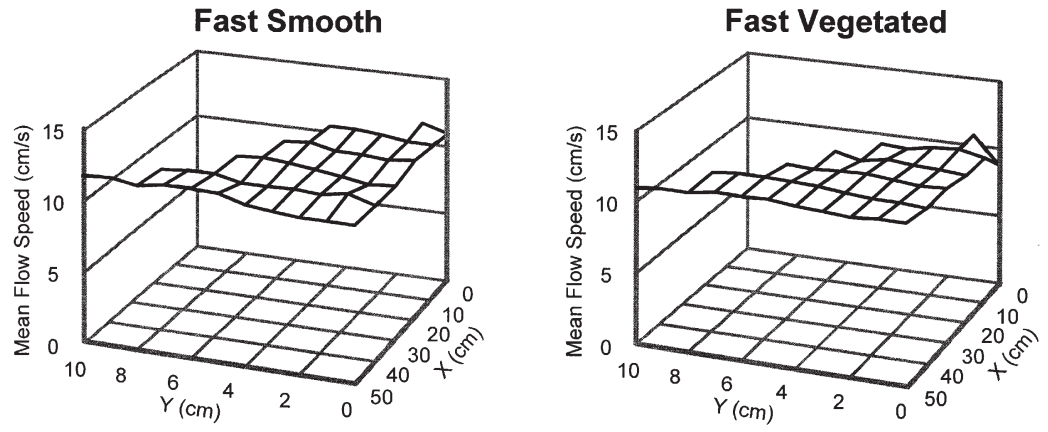

Fig. 3. Spatial distributions of mean flow velocity for each treatment combination during Trial 1 . Note the nearly uniform distributions throughout the plume. A slight decrease in mean velocity is detected at the source $(x=0, y=0)$, reflecting the influence of the slower moving odor solution at the plume outlet results in peaks in the time-series data (Fig. 6). Such time series vary within each plume and between treatments. However, they can be summarized by calculating mean conductivity $(=$ concentration), variance, number of peaks, peak heights, peak widths, and the intermittency (Fig. 6).

Regardless of flow or vegetation treatment, concentration mean and variance is highest at the source and gradually decreases with distance from the source and from the plume center (Figs. $7 \&$ 8). In the fast flow treatment, mean concentration near the plume source is about one-half that in the slow flow treatment (Fig. 7). This increased rate of dilution is more clearly seen in centerline profiles of relative conductivity (Fig. 9). In all treatments, mean conductivity was $\sim 1 \%$ of source values within $10 \mathrm{~cm}$ from the outlet (Fig. 9). At $x=2 \mathrm{~cm}$ from the plume source, mean conductivities in the slow treatments were more concentrated (8 to $16 \%$ of source concentration) than in the high data from all 40 locations into a single plot for each treatment combination and each day (Fig. 5). In each case, the plots show the majority of spectral energy to be concentrated at the lower frequencies, corresponding to larger eddies in the flume channel. In all treatments there is a sharp break in the spectral density at $\sim 1 \mathrm{~Hz}$; however, this break is more pronounced in the high flow treatment (Fig. 5). The action of vegetation mimics on turbulence is further evidenced in the slow flow treatment by a proportional increase in spectral energy at the highest frequencies during Trial 2 and Trial 3 (Fig. 5). The net effect of the vegetation mimics is to break up large energetic eddies to produce a more uniform flow environment (Fig. 4) dominated by smaller, less variable eddies (Fig. 5).

\section{Plume properties}

The movement of individual plume filaments past the conductivity sensor
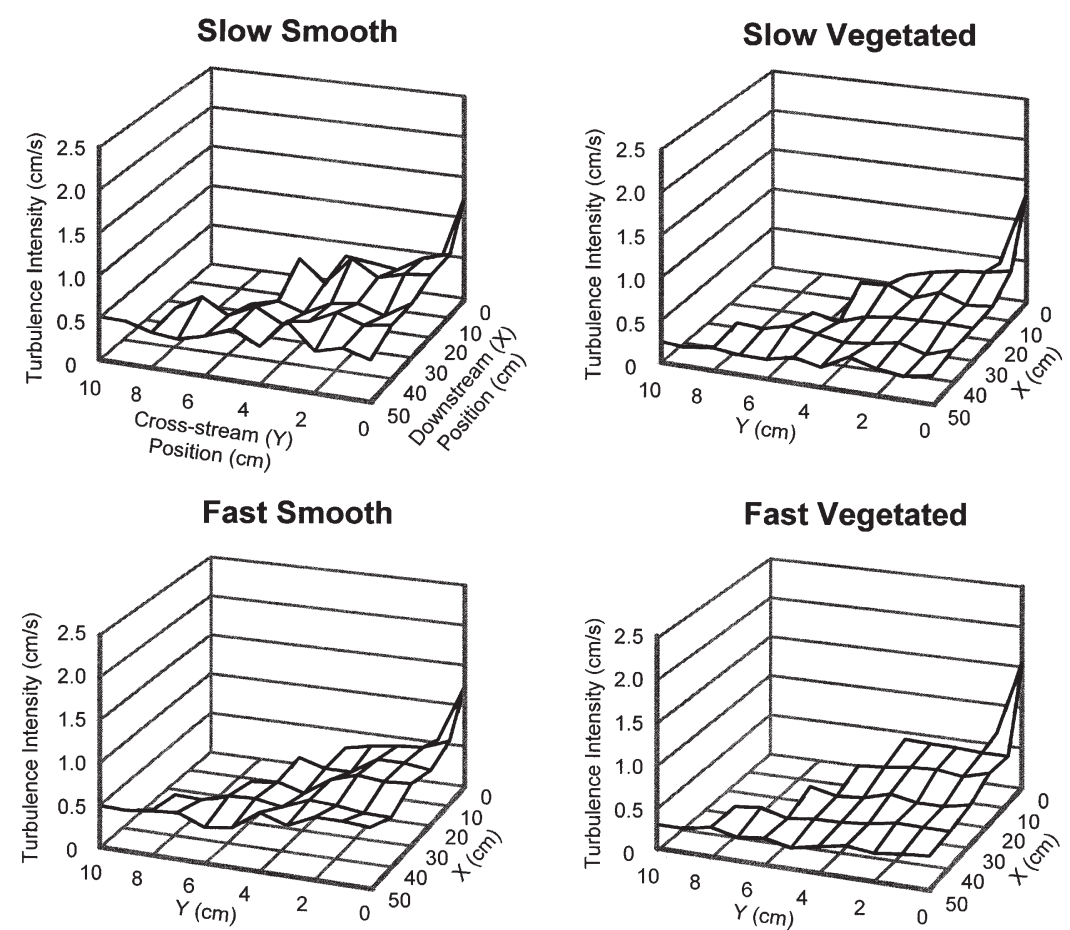

Fast Vegetated

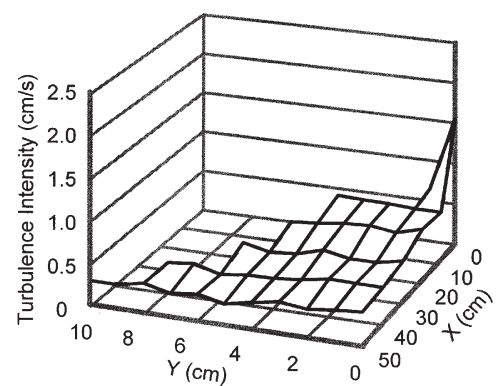

Fig. 4. Spatial distributions of the root-mean square turbulence intensity for each treatment combination during Trial 1. Turbulence intensity is highest near the plume source, reflecting the influence of the slower moving odor solution at the plume source 


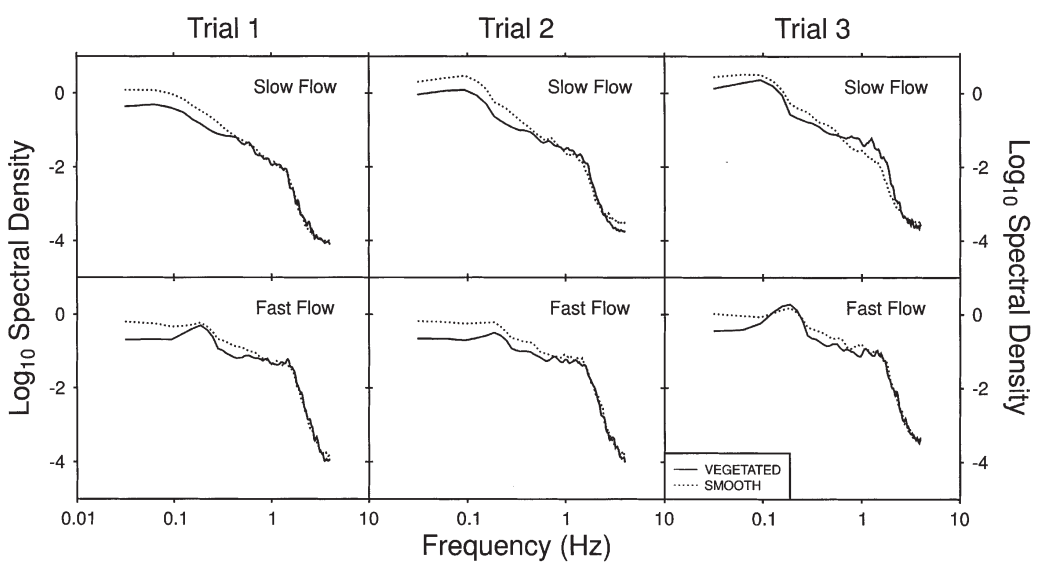

Fig. 5. Effects of flow speed and vegetation mimics on turbulent eddy structure during each trial. Each line reflects the mean spectral density computed from the 40 analyses performed for each plume a decrease in both cases. In general, plumes in the slow flow treatments are characterized by fewer peaks that are taller and of longer duration than in high flow treatments. The presence of vegetation mimics serves to further break up the plume, creating more odor filaments in both flow treatments. These odor filament properties combine to create patterns in the intermittency, which is higher in fast flows and in the presence of vegetation than in slow flows or smooth bottomed treatments. In all cases the downstream distance from the plume source ( $x$-position) was a significant negative covariate, indicating that plume properties decreased with distance from the plume source.

Both vegetation mimics and flow speed were important factors in cross-stream dispersal, showing significant or marginally significant effects in all analyses (Fig. 11). Both flow speed and vegetation cause significant increases in peak number $\left(\mathrm{ANCOVA}_{\text {; }}\right.$ flow treatment: $F_{1,67}=15.72, \mathrm{p}<0.001$; vegetation mimic treatment: $F_{1,67}=6.73, \mathrm{p}=0.012$ ) and intermittency (ANCOVA; data arcsine transformed; flow treatment: $F_{1,54}=3.25, \mathrm{p}<0.077$; vegetation mimic treatment: $F_{1,54}=5.63, \mathrm{p}=0.021$ ). In contrast, increased flow speed and the presence of vegetation mimics cause a decrease in peak height (ANCOVA; data log transformed; flow treatment: $F_{1,54}=26.03, \mathrm{p}<0.001$; vegetation mimic treatment: $F_{1,54}=7.71, \mathrm{p}=0.008$ ) and peak width (ANCOVA; data log transformed; flow treatment: $F_{1,54}=33.84, \mathrm{p}<0.001$; vegetation mimic

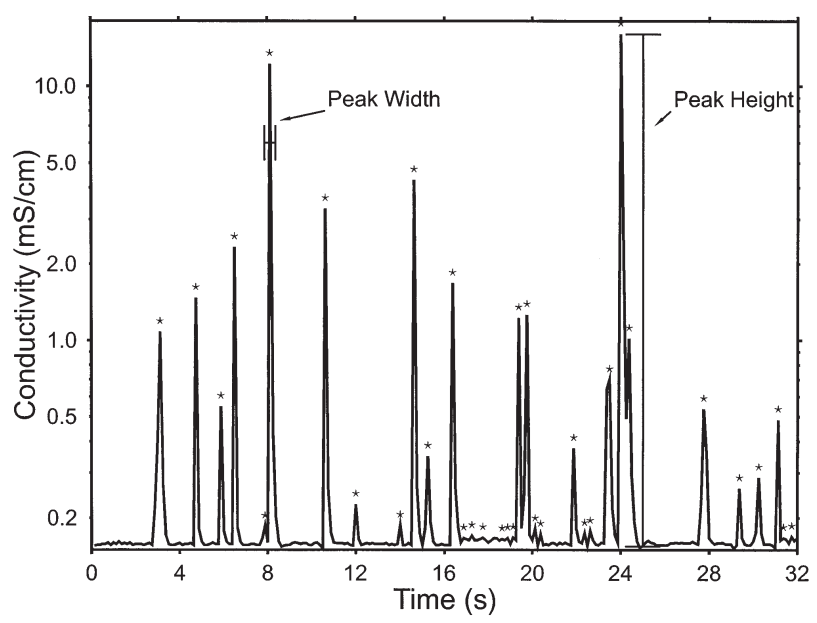

Fig. 6. Sample of conductivity data showing the filamentous nature of turbulent plumes. Stars represent the location of individual peaks. Peak height and peak width are also noted 


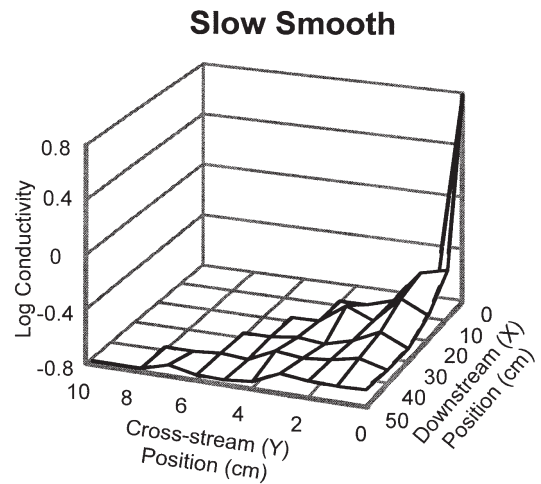

Fast Smooth

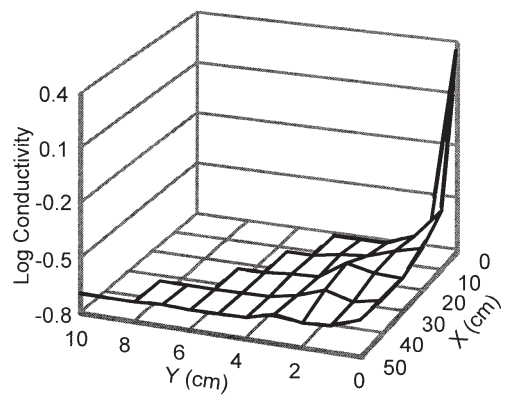

Slow Vegetated

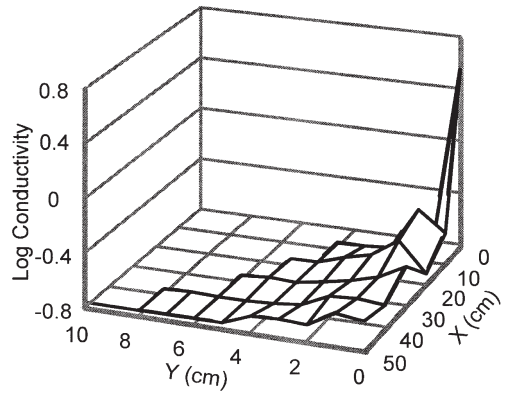

Fast Vegetated

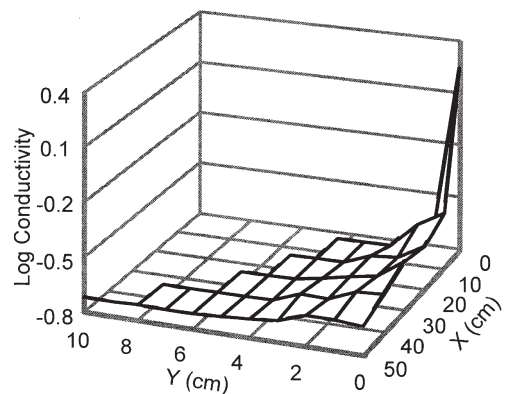

Fig. 7. Spatial distributions of mean conductivity (= concentration) for all 4 treatments during Trial 1

treatment: $\left.F_{1,67}=3.83, \mathrm{p}=0.056\right)$. In all analyses except that of peak height, the cross-stream position ( $y$-position) was negatively correlated with with plume filament properties. Peak heights do not change substantially with distance from the plume center.

Spectral analyses of conductivity time series from the plume mid-line show diminishing plume heterogeneity with increasing distance from the plume source. Spectral densities are higher at all frequencies close to the odor source, indicating greater variation in the time series of conductivity (Fig. 12). As the plume is mixed and concentrations become more homogeneous, spectral density decreases with distance from the source. In addition, the proportion of spectral energy found at high frequencies decreases with increasing distance from the plume source, reflecting a gradual decrease in the number and magnitude of odor peaks. The more homogeneous nature of plumes at high flow and in vegetated treatments is characterized by the generally lower spectral densities (slow vs fast) and overall com- pression of the data (smooth vs structured) (Fig. 12).

Diminishing temporal heterogeneity in conductivity is also noted in the cross-stream dimension. Spectral density plots are relatively flat close to the plume center, with a steady decrease in high frequency energy towards the plume edges (Fig. 13). This pattern reflects the gradual decline in the number of peaks with increasing distance from the plume center. The cross-stream decay of the odor plume is more gradual in faster flows than in slow flows, as indicated by the more graded decline in spectral density. The presence of vegetation mimics seems to enhance this gradient in both flow treatments.

\section{DISCUSSION}

Spatial patterns of odor plume dispersal result from 2 factors associated with flowing water: advection and turbulent mixing. Advection is directly

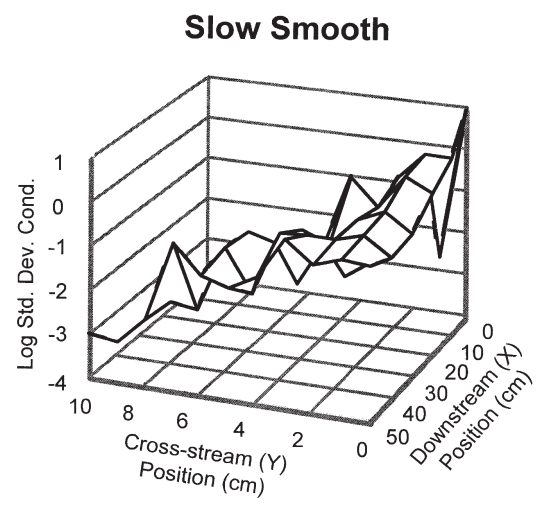

Fast Smooth

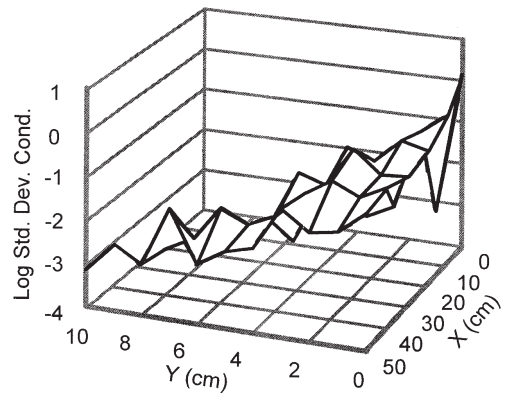

Slow Vegetated

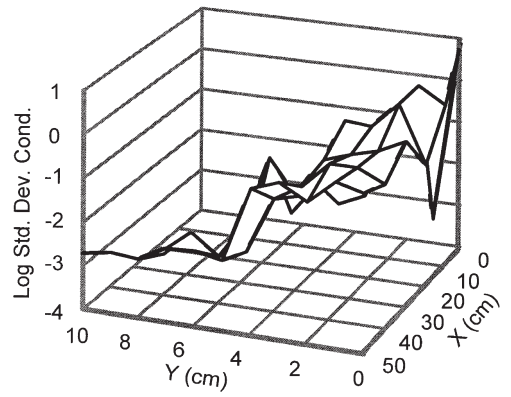

Fast Vegetated

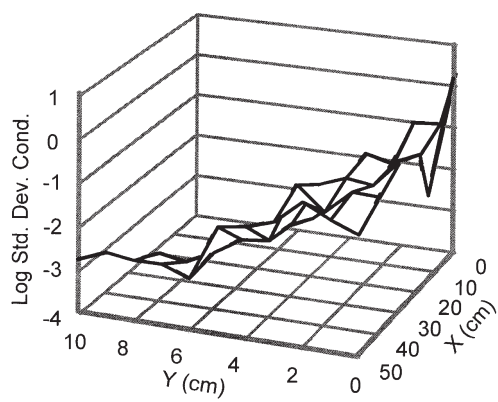

Fig. 8. Spatial distributions of the standard deviation of conductivity from each treatment during Trial 1 

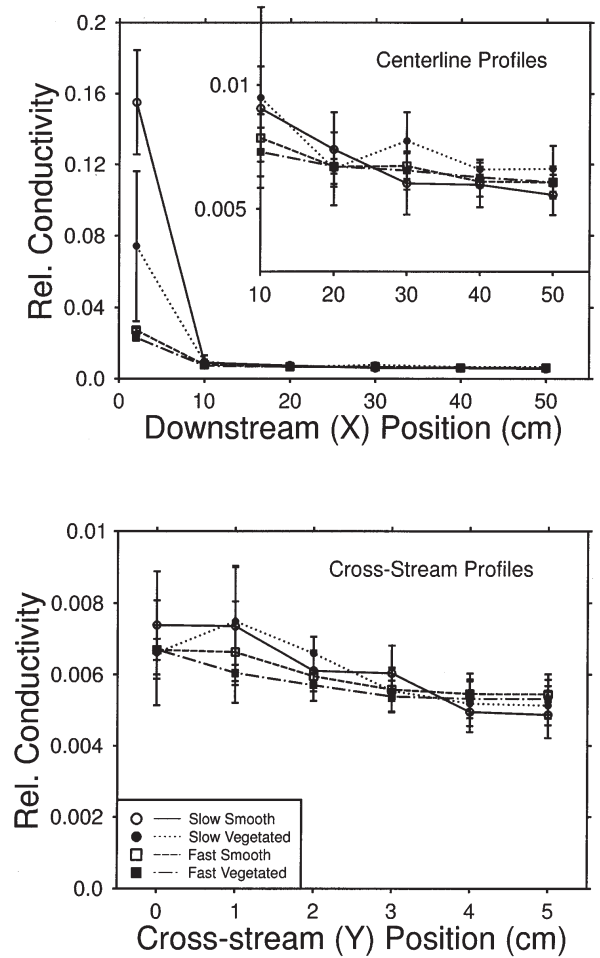

Fig. 9. Centerline and cross-stream profiles of relative conductivity (mean conductivity/source conductivity) showing the greater rates of dilution caused by increased flow speed. Treatment means computed from all 3 replicate days are plotted with standard deviations

related to the downstream component of water velocity and dictates the rate at which odor molecules are transported downstream from the plume source. Given equal release rates of dissolved material, plume concentrations in fast flows will be decreased relative to those in slower flows because the finite amount of odorant released per unit time is dispersed within a greater volume of water. This mechanism is consistent with my finding that flow speed, rather than the presence of vegetation mimics, was the primary control on mean concentration and peak height (Figs. 7, 9, 10 \& 11). For example, in the present study, odorant was released at $\sim 5.5 \mathrm{ml} \mathrm{min}^{-1}$. In the slow flow treatment $\left(\sim 5 \mathrm{~cm} \mathrm{~s}^{-1}\right)$, after $1 \mathrm{~s}, 0.09 \mathrm{ml}$ of odorant will be contained in a plume measuring $5 \mathrm{~cm}$ in length. In the high flow treatment, the same $0.09 \mathrm{ml}$ will be spread over a linear distance of $12 \mathrm{~cm}$, effectively decreasing the concentration by more than one-half (without considering the effects of lateral and vertical plume spread).
Turbulent mixing, the principle mechanism of vertical and lateral plume spread, can compound advective plume dilution and is primarily responsible for the genesis of odor filaments. The Principle of Local Exchange provides a mechanistic basis for understanding turbulence effects on plume dispersal (McNair et al. 1997). This theoretical construct specifies that the water column is divided into discreet water packets that move relative to each other due to the action of turbulent eddies. To preserve continuity, for each water parcel that moves an adjacent water parcel must fill its place. Hence, turbulent mixing occurs as the by-product of the reciprocal exchange of adjacent water packets, some of which contain dissolved material and some of which do not (McNair et al. 1997).

The mechanism suggested by the Principle of Local Exchange can be applied with success to the present study. For example, at the plume source initial exchange will be between odor-laden water in the plume axis and adjacent clean water, leading directly to the formation of odor filaments (e.g. List 1982, Mylne 1992). Because these filaments are cleaved from the main plume, they will initially retain characteristics of the main plume. So, in the high flow treatment where advection created plumes with lower overall concentration, the concentration within odor filaments (peak heights) was reduced as well (Figs. $10 \& 11$ ). The process of local exchange is repeated and the plume gradually grows laterally and vertically as turbulent eddies exchange water parcels from the plume axis with those farther on the plumes edges. Not all exchange occurs at the plume edges, and some mixing within the plume can be expected. For example, the number of odor

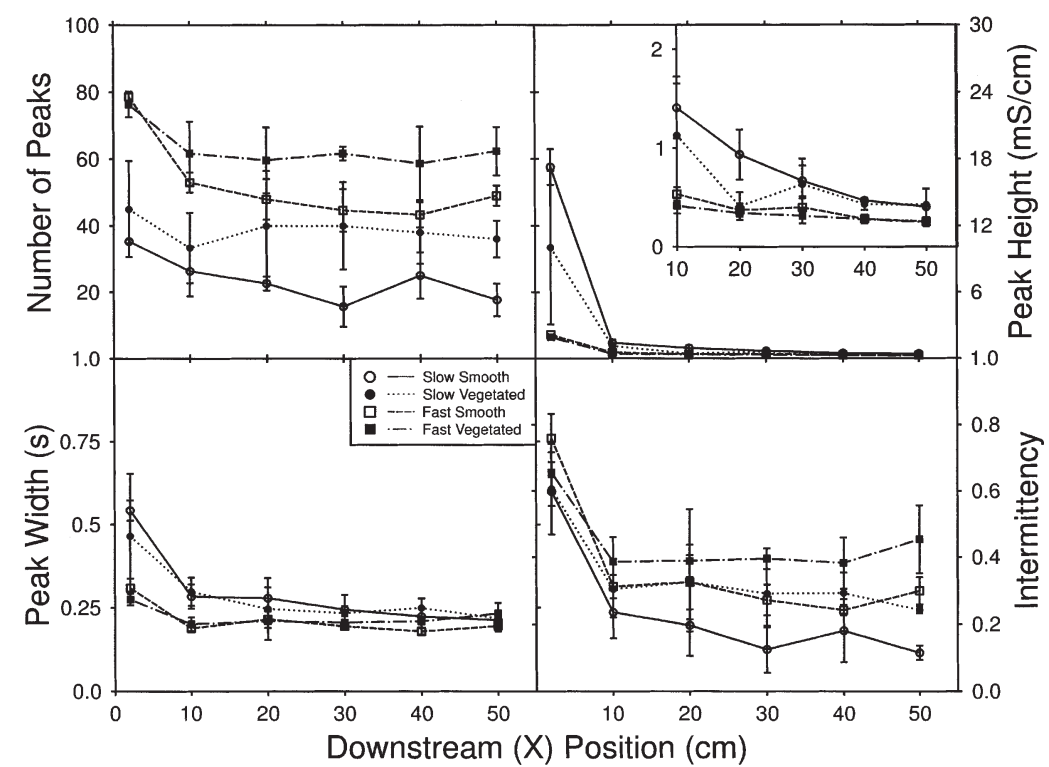

Fig. 10. Centerline profiles of odor filament properties. Treatment means computed from all 3 replicate days are plotted with standard deviations 


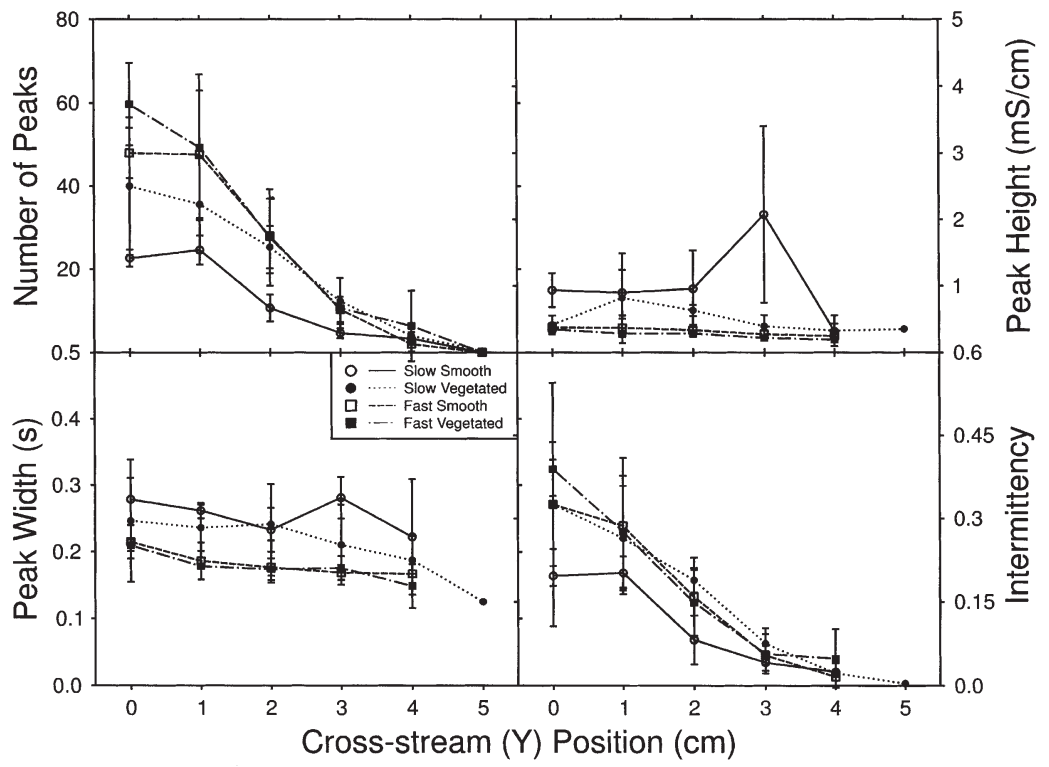

Fig. 11. Cross-stream profiles of odor filament properties. Profiles are taken from $20 \mathrm{~cm}$ from the plume source (e.g. $x=20$ ). Treatment means computed from all 3 replicate days are plotted with standard deviations the intermittency (Figs. 10 \& 11). These results confirm the importance of eddy structure and local exchange on the creation and dispersal of odor filaments.

Whether changes in odor plume structure induced by the presence of emergent vegetation, such as those documented here, will be reflected in the navigation abilities of organisms has yet to be seen. Examples from the literature point to different conclusions. For example, Willis et al. (1994) show that male moths have more direct flght paths to a pheromone source when an upstream obstruction (e.g. plastic cylinder mimicking a tree trunk) is directly upwind. They show that moths are better able to orient to the wider, more evenly distributed ('diffuse') plumes created by eddies shedding from the cylinder. In contrast, Weissburg \& Zimmer-Faust (1993) demonstrated that blue crabs have difficulty foraging in the presence of increased turbulent mixing. In their experiment, increased turbulence resulted in odors being rapidly diluted to below detectable levels. In this flume study the presence of Spartina alterniflora mimics created a more evenly distributed flow field and a more filaments in the centerline of a given plume remained fairly constant at distances $>10 \mathrm{~cm}$ from the plume source (Fig. 10). This pattern stems directly from the reciprocal exchange of like water parcels (e.g. each containing odorant) within the main axis of the plume. In contrast, the number of peaks declined in the crossstream direction as local exchange progressively transports odor filaments laterally (Fig. 11).

The size of water parcels exchanged and the rate at which the exchange occurs is determined by the spatial and temporal scales of turbulent eddies. The model Spartina alterniflora stand acted as a baffle that absorbed turbulent kinetic energy at low frequencies (large eddies) through friction, and released energy at higher frequencies (small eddies) via eddy shedding (Fig. 5, see also Laws \& Livesey 1978, Leonard \& Luther 1995). Moreover, because I chose a uniform spacing and stem size, velocity fluctuations in the vegetated treatments were more uniform than in the smooth bottomed treatments. These alterations in the eddy structure of the carrier flow increased the rate of local exchange and resulted in a significant increase in the number of odor filaments and in

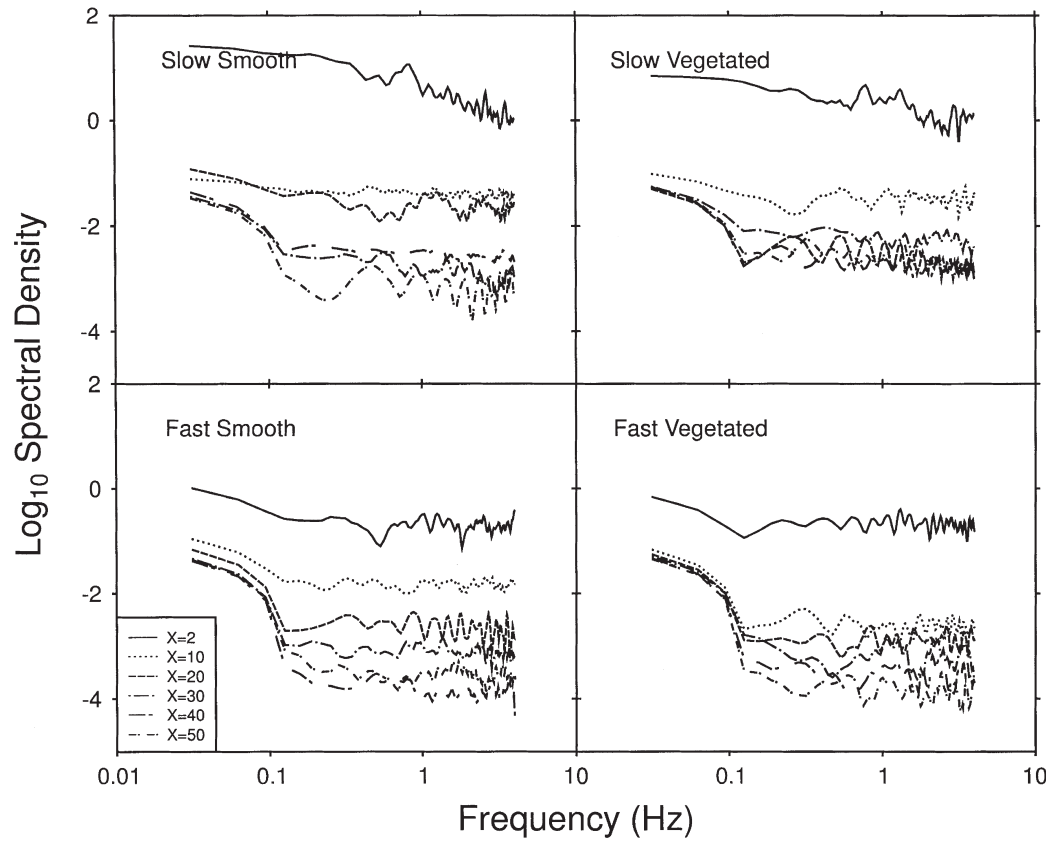

Fig. 12. Spectral density plots from the plume centerline in each treatment. Each plot is the composite mean for each treatment and downstream distance. The decrease in peak number and/or height with distance from the odor source is noted as a steady decline in spectral density at high frequencies. $x=$ downstream distance from plume source 


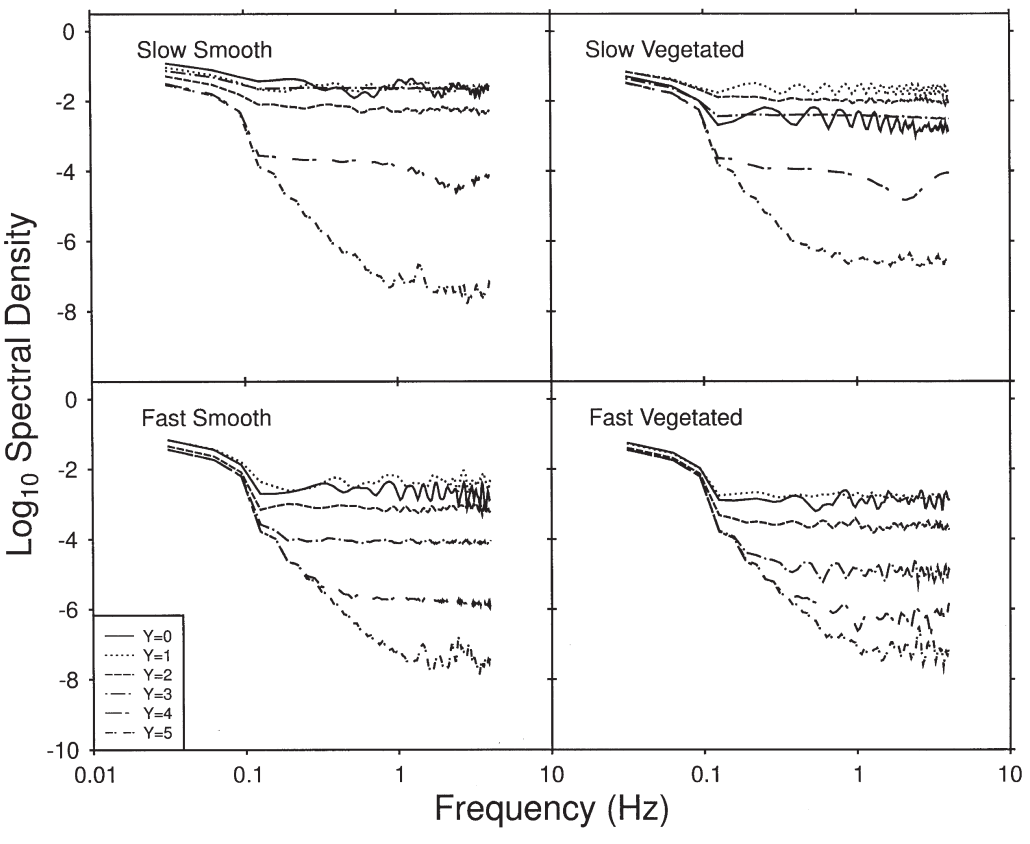

Fig. 13. Spectral density plots as a function of cross-stream distance. The decrease in peak number with distance from the plume center is noted as a steady decline in spectral density at high frequencies. $y=$ cross-stream distance from plume centerline

evenly distributed, although more dilute, plume. Therefore, marsh edge organisms are confronted by a more dilute, but potentially more stable chemical signal. Further experiments are needed to determine the conditions under which the benefits of a more evenly distributed plume are undermined by increased dilution in the presence of natural vegetation.

Navigating organisms are faced with 2 fundamental challenges when orienting to odor plumes. First, they must be able to detect when they are in a plume. This problem is one of 'edge detection', and is a function of both the timing of odor filaments and the concentration within each odor filament. Of course, odor concentration must be above a minimum threshold for it to be detected at all. The threshold for behavioral response to an odor is highly variable depending on the species involved and the immediate history of the particular individual (e.g. Zimmer-Faust et al. 1996). Previously, I (along with my colleagues) have argued that the signal intermittency might be a potent cue for organisms navigating turbulent plumes (Finelli et al. 1999). Edge detection via the intermittency would require that an organism only detect concentration greater than background levels. In the present study, the signal intermittency clearly defines the plume edge without regard for the absolute concentrations in the odor filament.

The second challenge faced by searching organisms is the determination of the direction to the plume source. Given the patchy distribution of odorant, mechanisms that rely on stable gradients in odor, such as classical chemotaxis, are not likely to be effective. Atema, Moore, and their colleagues have argued that the American lobster Homarus americanus can use information coded in individual odor filaments, especially the peak slope, to successfully follow an odor plume (Moore \& Atema 1988, 1991, Moore et al. 1991, 1994, Atema 1996). Atema (1996) refers to this mechanism as 'eddy chemotaxis' to distinguish it from classical chemotaxis. Because the lobster's chemoreceptors are held on long antenules away from the flow perturbations caused by the presence of its body and because some odor filament properties vary consistently within plumes, eddy chemotaxis may be an effective strategy (Atema 1996). However, there is some question as to whether lobsters and other marine organisms can sample quickly enough to detect variation in peak slopes (Finelli et al. 1999, but see Gomez et al. 1994, Gomez \& Atema 1996).

For organisms such as blue crabs, in which chemosensors (on legs and antenules) are held within the boundary layer surrounding the body, individual odor filaments may be smeared and some characteristics lost due to diffusional boundary layer effects (Cheer \& Koehl 1988, Moore et al. 1991, Berg et al. 1992, Gleeson et al. 1993). Under these circumstances reliance on odor filament properties may be ineffective, and the use of alternative strategies such as odor-conditioned rheotaxis may be more suitable (Weissburg \& ZimmerFaust 1993, Zimmer-Faust et al. 1995, Finelli et al. 2000). Using this strategy, an organism needs to detect only the edge of the plume to trigger upstream locomotion. This, too, could be accomplished by detection of intermittency.

The efficacy of both of the mechanisms described above (edge detection via intermittency and odorconditioned rheotaxis) may be enhanced in the presence of emergent vegetation. For example, the intermittency is increased in the presence of vegetation mimics regardless of flow speed, indicating that concentration is above background levels for a greater proportion of time. Moreover, the presence of vegetation mimics homogenized the flow field, perhaps making it easier to determine more precisely the direction of the odor source. If such enhancements to odormediated search can be demonstrated, then we must re-evaluate the utility of the marsh edge as a prey refuge from olfactory predators.

This study demonstrates the potential for emergent vegetation to alter flow conditions and odor dispersal 
marsh edge habitats. Both flow speed and vegetationlike structure, through their influence over local exchange and eddy sizes, alter the size, frequency, and concentration of odor filaments. Further studies are needed to test whether these changes will be reflected in the behavior of navigating organisms, and if so, whether searching will be enhanced or degraded. Such studies may help to understand the mechanisms that drive habitat use and ecological interactions among the many animals that use olfaction to find food, mates, and shelter.

Acknowledgements. This work was supported by grant no. G99-06 from the Marsh Ecology Research Program administered by the Academy of Natural Sciences and funded jointly by Sea Grant and New Jersey Public Service and Gas Company. Additional funding and facilities were provided by the Acadmey of Natural Sciences and the Louisiana Universities Marine Consortium. I am grateful for the editorial help of J. Pawlik. A. Wilson-Finelli, D. S. Wethey, and 2 anonymous reviewers provided useful comments on earlier drafts of this paper.

\section{LITERATURE CITED}

Atema J (1985) Chemoreception in the sea: adaptation of chemoreceptors and behavior to aquatic stimulus conditions. Soc Exp Biol Symp 39:387-423

Atema J (1996) Eddy chemotaxis and odor landscapes: exploration of nature with animal sensors. Biol Bull 191:129-138

Baltz DM, Rakocinski C, Fleeger JW (1993). Microhabitat use by marsh-edge fishes in a Louisiana estuary. Environ Biol Fishes 36:109-126

Bara BM, Wilson DJ, Zelt BW (1992) Concentration fluctuation profiles from a water channel simulation of a groundlevel release. Atmos Environ 26:1053-1062

Berg K, Voigt R, Atema J (1992) Flicking in the lobster Homarus americanus: recordings from electrodes implanted in antennular segments. Biol Bull 183:377-378

Box GEP, Jenkins GM, Reinsel GC (1994) Time series analysis: forecasting and control, 3rd edn. Prentice-Hall, Upper Saddle River, NJ

Cheer AYL, Koehl MAR (1988) Paddles and rakes: fluid flow through bristled appendages of small organisms. J Theor Biol 129:17-39

Decho AW, Browne KA, Zimmer-Faust RK (1998) Chemical cues: why basic peptides are signal molecules in marine environments. Limnol Oceanogr 43:1410-1417

Eckman JE (1983) Hydrodynamic processes affecting benthic recruitment. Limnol Oceanogr 28:241-257

Finelli CM, Pentcheff ND, Zimmer-Faust RK, Wethey DS (1999) Odor transport in turbulent flows: constraints on animal navigation. Limnol Oceanogr 44:1056-1071

Finelli CM, Pentcheff ND, Zimmer-Faust RK, Wethey DS (2000) Physical constraints on ecological processes: a field test of odor-mediated foraging. Ecology 81:784-797

Gleeson RA, Carr WES, Trapido-Rosenthal HG (1993) Morphological characteristics facilitating stimulus access and removal in the olfactory organ of the spiny lobster, Panulirus argus: insight from design. Chem Senses 18:67-75

Gomez G, Atema J (1996) Temporal resolution in olfaction: stimulus integration time of lobster chemoreceptor cells. J Exp Biol 199:1771-1779
Gomez G, Voigt R, Atema J (1994) Frequency filter properties of lobster chemoreceptor cells determined with highresolution stimulus measurement. J Comp Physiol A 174: 803-811

Hart DD, Clark BD, Jasentulyana A (1996) Fine scale field measurement of benthic flow environments inhabited by stream insects. Limnol Oceanogr 41:297-308

Kneib RT (1997) The role of tidal marshes in the ecolgy of estuarine nekton. Oceanogr Mar Biol Annu Rev 35:163-220

LaBarbara M, Vogel S (1976) An inexpensive thermistor flowmeter for aquatic biology. Limnol Oceanogr 21:750-756

Laws EM, Livesey JL (1978). Flow through screens. Annu Rev Fluid Mech 10:247-266

Leonard LA, Luther ME (1995) Flow hydrodynamics in tidal marsh canopies. Limnol Oceanogr 40:1474-1484

List EJ (1982) Turbulent jets and plumes. Annu Rev Fluid Mech 14:189-212

Matthewson RF, Hodgson ES (1972) Klinotaxis and rheotaxis in orientation of sharks toward chemical stimuli. Comp Biochem Physiol A 42:79-84

McNair JN, Newbold JD, Hart DD (1997) Turbulent transport of suspended particles and dispersing benthic organisms: how long to hit bottom? J Theor Biol 188:29-52

Micheli F (1996) Predation intensity in estuarine soft bottoms: between-habitat comparisons and experimental artifacts. Mar Ecol Prog Ser 141:295-302

Micheli F (1997) Effects of predatory foraging behavior on patterns of prey mortality in marine soft bottoms. Ecol Monogr 67:203-224

Minello TJ, Webb JW (1997) Use of natural and created Spartina alterniflora salt marshes by fishery speciees and other aquatic fauna in Galveston Bay, Texas, USA. Mar Ecol Prog Ser 151:165-179

Minello TJ, Zimmerman RJ, Medina R (1994) The importance of edge for natant macrofauna in a created salt marsh. Wetlands 14:184-198

Moore PA, Atema J (1988) A model of a temporal filter in chemorecption to extract directional information from a turbulent plume. Biol Bull 174:355-363

Moore PA, Atema J (1991) Spatial information in the threedimensional fine structure of an aquatic odor plume. Biol Bull 181:408-418

Moore PA, Scholz N, Atema J (1991) Chemical orientation of lobsters, Homarus americanus, in turbulent odor plumes. J Chem Ecol 17:1293-1307

Moore PA, Weissburg MJ, Parrish JM, Zimmer-Faust RK, Gerhardt GA (1994) Spatial distribution of odors in simulated benthic boundary layer flows. J Chem Ecol 20:255-279

Murlis J, Jones CD (1981) Fine scale structure of odour plumes in relation to insect orientation to distant pheromone and other attractant sources. Physiol Entomol 6:71-86

Mylne KR (1992) Concentration fluctuation measurements in a plume dispersing in a stable surface layer. Boundary Layer Meteorol 60:15-48

Nevitt GA, Veit RR, Kareiva P (1995) Dimethyl sulphide as a foraging cue for Antarctic Procellariiform seabirds. Nature 376:680-682

Nowell ARM, Jumars PA (1984) Flow environments of aquatic benthos. Annu Rev Ecol Syst 15:303-328

Pawlik JR (1992) Chemical ecology of the settlement of benthic marine invertebrates. Oceanogr Mar Biol Annu Rev 30:273-335

Peterson GW, Turner RE (1994) The value of salt marsh edge vs interior as a habitat for fish and decapod crustaceans in a Louisiana tidal marsh. Estuaries 17:235-262

Press WH, Teukolsky SA, Vetterling WT, Flannery BP (1992) 
Numerical recipes in C, 2nd edn. Cambridge University Press, Cambridge

Sand-Jensen K, Mebus JR (1996) Fine-scale patterns of water velocity within macrophyte patches in streams. Oikos 76: 169-180

SAS Institute (1993) SAS/ETS users guide, Version 6. SAS Institute, Cary, NC

Valentinčič T (1991) Behavioral responses of the brittle star Ophiura ophiura to amino acids, acetylcholine and related low-molecular-weight compounds. Chem Senses 16: 251-266

Weissburg MJ, Zimmer-Faust RK (1993) Life and death in moving fluid: hydrodynamic effects on chemosensorymediated predation. Ecology 74:1428-1443

Willis MA, David CT, Murlis J, Carde RT (1994) Effects of

Editorial responsibility: Joseph Pawlik (Contributing Editor), Wilmington, North Carolina, USA pheromone plum structure and visual stimuli on the pheromone-modulated upwind flight of male gypsy moths (Lymantria dispar) in a forest (Lepidoptera: Lymantriidae). J Insect Behav 7:385-409

Zar JH (1996) Biostatistical analysis, 3rd edn. Prentice Hall, Englewood Cliffs, NJ

Zimmer-Faust RK, Stanfill JM, Collard SB (1988) A fast, multichannel fluorometer for investigating aquatic chemoreception and odor trails. Limnol Oceanogr 33:1586-1595

Zimmer-Faust RK, Finelli CM, Pentcheff ND, Wethey DS (1995) Odor plumes and animal navigation in turbulent water flow: a field study. Biol Bull 188:111-116

Zimmer-Faust RK, O'Neill P, Schar DW (1996) The relationship between predator activity state and sensitivity to prey odor. Biol Bull 190:82-87

Submitted: April 25, 2000; Accepted: August 15, 2000

Proofs received from author(s): October 17, 2000 